\title{
CARTA AOS AUTORES
}

\author{
Saul Goldenberg ${ }^{1}$, Tânia Pereira Morais Fino² \\ 1. Editor Chefe Acta Cirúrgica Brasileira \\ 2. Revisora Acta Cirúrgica Brasileira
}

Este editorial é um apelo dirigido aos nossos usuários.

Apelo aos nossos colaboradores, que prestem mais atenção às normas e ao estilo da nossa revista Acta Cirúrgica Brasileira, antes de enviarem os seus artigos.

As desatenções, distrações, descumprimento das normas, desleixo, negligência, descaso, desrespeito às convenções nacional [idioma português], internacional [inglês], desconsideração à nomenclatura e terminologia vigentes estão cada vez mais freqüentes.

As agências como a CAPES, CNPq, FAPESP, SciELO, MEDLINE, EXCERPTA MEDICA, ISI e leitores exigentes avaliam os artigos publicados e observam "com lente de aumento" a forma, o conteúdo científico e o esmero na padronização das normas da publicação.

Norma é aquilo que regula procedimentos, cumpre regras a fim de se atingir um padrão de excelência. Norma caracteriza disciplina. Normalizar é salutar

A Revista Acta Cirúrgica Brasileira adotou uma padronização a fim de tornar uniforme a publicação.

\section{OCORRENNCIAS FREQUENTES NOS ARTIGOS ENVIADOS A ACTA CIRÚRGICA BRASILEIRA}

1. Falta de consulta às instruções aos autores que constam na própria revista e que podem ser acessadas em www.scielo.br/acb. Ou, deixar de consultar exemplares recentes da revista para servirem de modelo.

\section{1 - Não se cumpre esta exigência:}

Os autores cujos trabalhos forem aceitos para publicação pela revista transferem todos os direitos de reprodução (copyright) a Acta Cirúrgica Brasileira. Uma carta contendo essa declaração deve ser encaminhada junto com o trabalho, assinada por todos os autores. O primeiro autor assume a responsabilidade de que todos os autores concordaram com o conteúdo do artigo enviado.

De acordo com o Ato de Direitos Autorais de 1976, todos os artigos devem anexar a seguinte declaração:”Os autores abaixo assinados transferem todos os direitos autorais do artigo intitulado “ á Acta Cirúrgica Brasileira. Garantem que o artigo é original, não infringe qualquer direito autoral ou direito à propriedade de terceiros, não está em avaliacão por outro periódico e não foi previamente publicado. $\mathrm{O}$ trabalho foi lido e cada contribuição foi aprovada." Nome legível e assinatura dos autores.

1.2 - Os originais devem ser enviados por e-mail (sgolden@terra.com.br), e escritos no idioma inglês. A Revista tem preferência pelo Word for Windows 7.0.

1.3 - Os originais devem incluir: título (nos idiomas inglês e português), resumo/abstract, introdução, métodos, resultados, discussão, conclusão e referências (agradecimento, se houver). Não se aceita unir capítulos, como "resultados e discussão" ou "resultados e conclusões"

1.4-Ética: Os autores devem seguir o CIOMS (Council for International Organization of Medical Sciences) ethical code for animal experimentation ${ }^{2}$ e os preceitos do Colégio Brasileiro de Experimentação Animal (COBEA) $)^{\mathbf{3 , 4 5}}$. Pesquisas em seres humanos devem ser aprovadas pelo Comitê de Ética da Instituição onde o trabalho foi realizado, cumprindo Resolução n. 196/96 do Conselho Nacional de Saúde. Enviar cópia do certificado do Comitê.

2. Erros na titulação acadêmica dos autores, no idioma inglês ${ }^{6}$

3. Resumo/Abstract estruturados conforme norma da revista. Aparecem descuidos no que se refere aos idiomas e no conteúdo informativo.

4. Falta, freqüente, na consulta ao $\operatorname{DeCS}^{7,8}$ (Descritores em Ciências da Saúde). Os descritores/key words são essenciais para a acessibilidade e recuperação dos artigos. Facilita o acesso à informação e guia os usuários na localização e seleção da informação científica. A inclusão de descritores que não constam no DeCS impede a localização do artigo. Se os autores desejarem que seus artigos sejam encontrados torna-se imperioso pesquisar no DeCS os termos convencionados.

5. Freqüentemente os autores não cumprem o estilo Vancouver no texto e nas referências ${ }^{9}$

A Revista Acta Cirúrgica Brasileira não adota ordem alfabética. As referências são numeradas na ordem de 
entrada no texto. Nas referências todos os autores devem ser citados. Não se aceita nas referências o "et al". As abreviaturas dos periódicos devem cumprir o Index Medicus.

6. Os autores não indicam, no texto, os locais das tabelas e das figuras, com as respectivas legendas. Muitas vezes as legendas não explicam o que as figuras mostram, dificultando o entendimento do leitor. As tabelas devem ter o enunciado acima e as figuras devem ter as legendas, abaixo.

Acrescente-se a falta de qualidade das ilustrações, prejudicando a reprodução e impressão.

As ilustrações devem ser enviadas em cores.

7. Negligência no cumprimento das normas referentes à Nomenclatura/Terminologia ${ }^{10}$.

8. Descuido no levantamento bibliográfico. É freqüente a não citação de autores nacionais, inclusive de artigos da própria revista publicados na SciELO e falta de pesquisa no Medline/PubMed.

9. Omissão na informação do endereço completo do primeiro autor, tel/fax, e-mail.

10. Declaração do CONFLITO DE INTERESSE (a fim de cumprir a Resolução do Conselho Federal de Medicina n.1595/2000, que veda "artigos, mensagens e materiais promocionais de produtos ou equipamentos de uso na área médica").

$\mathrm{O}$ autor deve informar a(s) fonte(s) de financiamento do trabalho, se houver, com o número do processo.

A Revista Acta Cirúrgica Brasileira não aceita relato de caso ou artigos retrospectivos.

Artigos de "revisão e atualização" são encomendados pelo Corpo Editorial.
Em suma, os autores enviam os artigos sem a devida e cuidadosa revisão.

Consultar www.scielo.br/acb e exemplar recente da revista a fim de seguir as normas e o estilo adotados.

Dúvidas, perguntas e esclarecimentos podem ser endereçadas por e-mail: sgolden@terra.com.br, por Tel/Fax: (11) 3287-8814 ou pelo correio.

\section{REFERÊNCIAS}

1. Goldenberg S. Normalizar é salutar. Acta Cir Bras. 2000;15(2):79. Disponível em www.scielo.br/acb.

2. Council for International Organization of Medical Sciences (CIOMS). WHO Chronicle. 1985;39(2):51-6.

3. Legislação e ética. Colégio Brasileiro de Experimentação Animal (COBEA). Disponível em: http://www.cobea.org.br/ética

4. De Luca RR, Alexandre SR, Marques T, Souza NL, Merusse JLB, Neves SP. Manual para técnicos em bioterismo. São Paulo: Winner Graph; 1996.

5. Goldenberg S. Aspectos éticos da pesquisa com animais.Acta Cir Bras.2000;15(4):193-4. Disponível em www.scielo.br/acb.

6. Goldenberg S, Matone J. Academic degrees: standardization in english language. Acta Cir Bras. 2006;21(2):60. Disponível em www.scielo.br/acb.

7. Descritores em Ciências da Saúde (DeCS). Disponível em: http://www.bireme.br

8. Pellizzon R F. Pesquisa na área da saúde: 1. Base de dados DeCS (Descritores em Ciências da Saúde). Acta Cir Bras. 2004; 19(2):153-63.

9. Uniform requirements for manuscripts submitted to biomedical journals: writing and editing for biomedical publication. 2006 [update 2006 feb]. Available from: http://www.icmje.org

10. Terminologia anatômica. São Paulo: Ed. Manole; 2001.

\section{Correspondência:}

Prof. Saul Goldenberg

Alameda Rio Claro, 179/14 ${ }^{\circ}$ andar

01332-010 São Paulo-SP Brasil

Tel/Fax:(11)3287-8814

sgolden@terra.com.br 